\title{
ASO Visual Abstract: Significance of Antimicrobial Prophylaxis for Prevention of Early-Onset Pneumonia after Radical Esophageal Cancer Resection: A Retrospective Analysis of 356 Patients Undergoing Thoracoscopic Esophagectomy
}

Eiji Higaki, MD, $\mathrm{PhD}^{1}$ (D), Tetsuya Abe, $\mathrm{MD}, \mathrm{PhD}^{1}$, Hironori Fujieda, MD, $\mathrm{PhD}^{1}$, Takahiro Hosoi, MD, $\mathrm{PhD}^{\mathbf{1}}$, Takuya Nagao, MD ${ }^{1}$, Koji Komori, MD, PhD ${ }^{1}$, Seiji Ito, MD, PhD ${ }^{1}$, Naoya Itoh, MD, DTM\& ${ }^{2}$, Keitaro Matsuo, $\mathrm{MD}, \mathrm{PhD}^{3,4}$, and Yasuhiro Shimizu, $\mathbf{M D}, \mathbf{P h D}^{1}$

${ }^{1}$ Department of Gastroenterological Surgery, Aichi Cancer Center Hospital, Nagoya, Aichi , Japan; ${ }^{2}$ Division of Infectious Diseases, Aichi Cancer Center Hospital, Nagoya, Japan; ${ }^{3}$ Division of Cancer Epidemiology and Prevention, Aichi Cancer Center Research Institute, Nagoya, Japan; ${ }^{4}$ Division of Cancer Epidemiology, Nagoya University Graduate School of Medicine, Nagoya, Japan

It remains unclear whether antimicrobial prophylaxis can prevent pneumonia after radical resection of esophageal cancer. The current study demonstrated that ampicillin/sulbactam (ABPC/SBT) compared with cefazolin (CEZ) as a prophylactic antimicrobial agent reduced the incidence of early-onset pneumonia after thoracoscopic esophagectomy (https://doi.org/10.1245/s10434-021-10867-5).

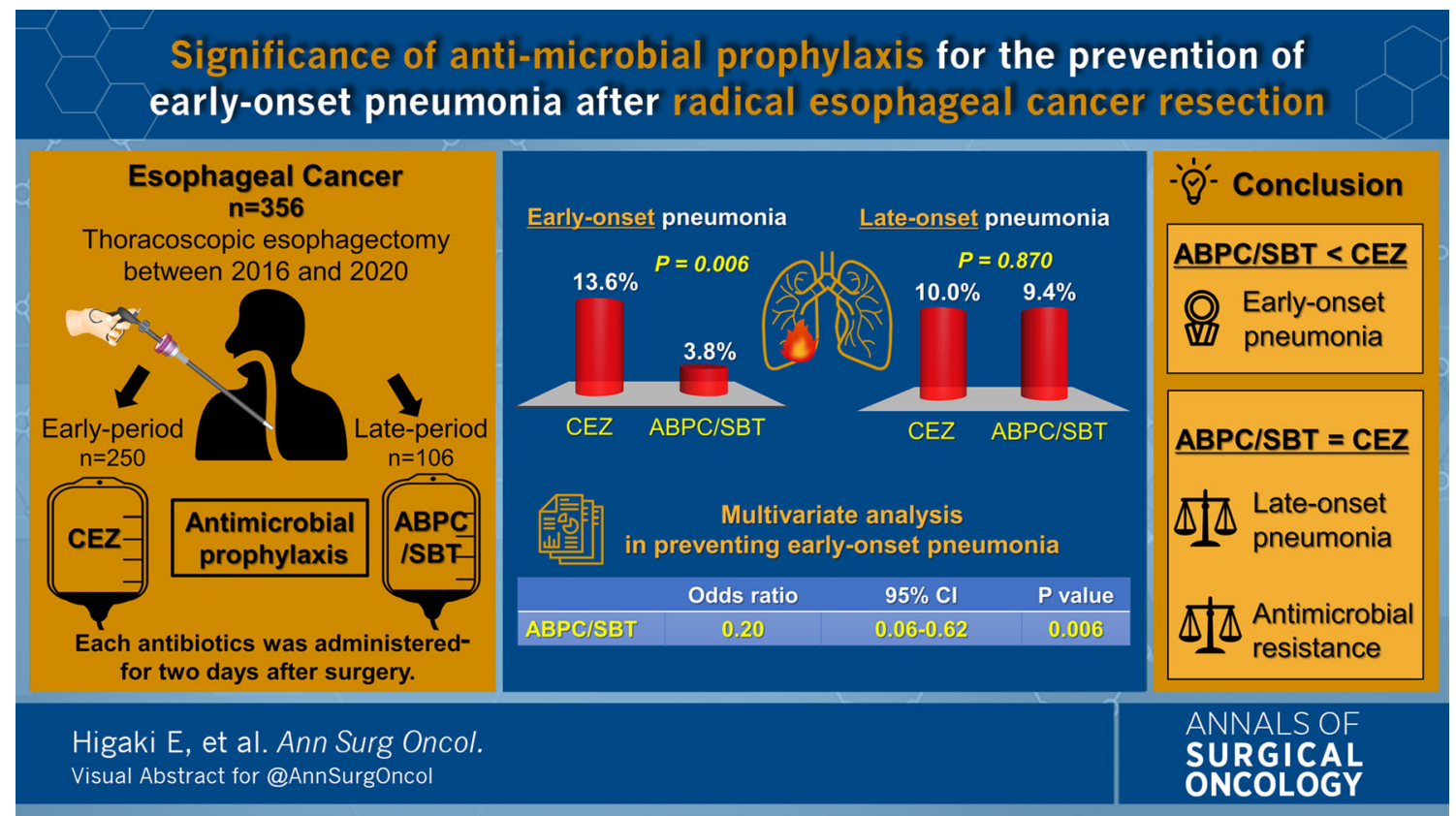

(C) Society of Surgical Oncology 2021

Published Online: 27 October 2021

E. Higaki, MD, $\mathrm{PhD}$

e-mail: ehigaki@aichi-cc.jp
DISCLOSURE All of the authors declare that they have no conflict of interest.

Publisher's Note Springer Nature remains neutral with regard to jurisdictional claims in published maps and institutional affiliations. 